DOI 10.21680/1517-7874.2020v22n1ID19292

\title{
REFLEXÕES SOBRE LETRAMENTO CRÍTICO NAS AULAS DE LÍNGUA ESTRANGEIRA A PARTIR DE PERSPECTIVA TRAZIDA PELA BASE NACIONAL COMUM CURRICULAR
}

\section{REFLECTIONS ON CRITICAL TEACHING IN FOREIGN LANGUAGE CLASSES FROM THE PERSPECTIVE BROUGHT BY THE COMMON NATIONAL CURRICULAR BASE}

\author{
Jéssica Daiane Levandovski Thewes ${ }^{1}$ \\ Daiana Steyer ${ }^{2}$ \\ Cátia de Azevedo Fronza ${ }^{3}$ \\ Universidade do Vale do Rio dos Sinos (UNISINOS)
}

\begin{abstract}
RESUMO
No atual contexto social, permeado por todos os tipos de veículos comunicativos, por vezes texto e imagem não são correlacionados para a construção do sentido. Nessa perspectiva, não se percebe a experiência de leitura como prática social e, consequentemente, o leitor não adota uma postura crítica frente ao texto. Neste artigo, destaca-se o papel da escola para o desenvolvimento dessas competências. Em vista disso, propõe-se uma reflexão acerca da relevância de atividades de letramento crítico na sala de aula. Busca-se discutir sobre como o letramento crítico e o ensino de língua estrangeira estão imbricados e como são tratados pela Base Nacional Comum Curricular (BNCC, 2017). Valemo-nos dos estudos de Mello e Teixeira (2012), quando se referem aos múltiplos formatos de texto no âmbito tecnológico. Consideramos ainda Pinheiro (2016a; 2016b; 2019), Filho (2003) e Abrahão (2012) para discutir o letramento crítico na sala de aula de língua estrangeira, os estilos e formas de aprendizagem, respectivamente. Coadunamos com a perspectiva sociocultural de Vygotsky, focalizando a relevância da interação para a aprendizagem. Nesta ótica, aspira-se a discutir sobre como a prática pedagógica da cultura digital contribui para a participação mais efetiva e crítica nas atividades contemporâneas de linguagem, em situação escolar. Para as reflexões pretendidas, são considerados dados de conversas e entrevistas realizadas com professoras de escola de surdos da região metropolitana de Porto Alegre e a prática pedagógica de Pinheiro (2016a) com alunos do Ensino Médio.A partir desses dados, faz-se uma reflexão acerca de como impulsionar o desenvolvimento de práticas que promovem o agenciamento crítico dos estudantes para exercício da cidadania ativa. Esta análise reflete que a aprendizagem significativa emerge de atividades conectadas com o contexto dos alunos.Entendemos, assim, que práticas de letramento devem permear a aprendizagem em todas as áreas de conhecimento, não se restringindo ao ensino de línguas.
\end{abstract}

PALAVRAS-CHAVE:Língua Estrangeira; Letramento Crítico; BNCC.

\begin{abstract}
In the current social context, permeated by all kinds of communicative vehicles, sometimes text and image are not correlated for the construction of meaning. In this perspective, reading experience is not conceived as a social practice and, consequently, the reader does not use a critical posture towards the text. In this article, the role of the school in the development of these

\footnotetext{
${ }^{1}$ Mestranda do Programa de Pós-graduação em Linguística Aplicada pela Universidade do Vale do Rio dos Sinos (Unisinos). E-mail: jessica.levandovski@yahoo.es

${ }^{2}$ Mestre pelo Programa de Pós-graduação em Linguística Aplicada pela Universidade do Vale do Rio dos Sinos (Unisinos). E-mail:daiana-steyer@ hotmail.com

${ }^{3}$ Docente do Programa de Pós-graduação em Linguística Aplicada pela Universidade do Vale do Rio dos Sinos (Unisinos). E-mail: catiaaf@unisinos.br
} 
competencies is highlighted. In view of this, we propose a reflection on the relevance of critical literacy activities in the classroom. We seek to discuss how critical literacy and foreign language teaching are intertwined and how they are approached by the National Common Curriculum Base (BNCC, 2017). We relied on studies by Mello and Teixeira (2012), when they refer to the multiple text formats in the technological field. We also considered Pinheiro (2016a; 2016b; 2019), Filho (2003) and Abrahão (2012) to discuss critical literacy in a foreign language classroom, styles and forms of learning, respectively. We agreed with Vygotsky's sociocultural perspective, focusing on the relevance of interaction for learning. In this perspective, we aim to discuss how the pedagogical practice of digital culture contributes to a more effective and critical participation in contemporary language activities in school situations. For the intended reflections, data from conversations and interviews conducted with deaf school teachers in the metropolitan region of Porto Alegre and the pedagogical practice of Pinheiro (2016a) with high school students are considered. Based on these data, there is a reflection on how to advance the development of practices that promote critical agency of students for the exercise of active citizenship. This analysis reflects that meaningful learning emerges from activities connected to the students' context. Thus, we understand that literacy practices should permeate learning in all areas of knowledge, not being restricted to language teaching.

KEYWORDS:Foreign language; Critical literacy; BNCC.

\section{INTRODUÇÃO}

Em uma sociedade semiotizada, permeada por gêneros multimodais que, cada vez mais, "conversam" com os leitores, as demandas educacionais, principalmente as que tangenciam o ensino de línguas, assumem novas formas. Nesse contexto, aspectos como a multiculturalidade ganham espaço dentro do discurso, em especial quando se trata do ensino de línguas estrangeiras. Em um contexto de globalização, o aumento do contato entre as mais diversas culturas exige novas habilidades para que possamos entender e assimilar a tecnologia digital.

Essasmudançasno contexto escolar ocorrem a passos lentos desde que começaram a emergir em decorrência de novas demandas sociais.Martinez e Peric (2009)apontam que o início se deu por volta dos anos 1980, com a Revolução Industrial. A partir daí, o currículo escolar passou a ser transformado, voltado para o ensino instrumental, de modo a capacitar os estudantes para atuar no mercado de trabalho industrializado. Procurandosituar o lugar da língua estrangeira nesse dado momento histórico, vale ressaltar que o ensino foi marcado fortemente por exercícios de tradução. Assim, a proximidade com a tecnologia foi impulsionada, mas com a finalidade específica do trabalho. Segundo Campani (2006), as atividades com textos nas aulas não significavam práticas de leitura, e a autora também destaca o distanciamento entre professor e aluno, sendo o primeiro o "detentor" do saber. Diante disso, a implementação de novas referências, não só para o ensino de língua estrangeira, como para todo o sistema educacional brasileiro, tais como a Lei de Diretrizes e Bases da Educação Nacional (LDBEN), os Parâmetros Curriculares Nacionais (PCN's) e, recentemente, a Base Nacional Comum Curricular (BNCC) contribuíram para novas perspectivas do ensino e da aprendizagem.

Esses documentos explicitam a obrigatoriedade da oferta de língua estrangeira, focalizando o inglês. Na BNCC, a língua inglesa é contemplada como promotora de novas formas de engajamento no mundo social globalizado e plural, atravessada pelas múltiplas culturas e interesses sociais diversos. Nessa perspectiva, práticas de ensino mecanizadas são negligenciadas, dando espaço ao conhecimento co-construído.

Sob esta ótica, surge uma nova forma de ensinar e de aprender. O protagonismo do professor abre-se para o protagonismo do aluno, e o aprendizado se dá por meio de uma prática social. Assim, o aluno passa a exercitar uma postura crítica frente à realidade que o cerca, e o processo de interação com outras pessoas e com o mundo são potencializados. Em vista disso, 
Mello e Teixeira (2012) explicitam os inúmeros outros formatos de textos que emergiram do avanço tecnológico e que promovem essa interação:
À medida em que as tecnologias superam as limitações de representação de informações e, no decorrer dos anos, passam a oferecer não somente o texto como único suporte, mas uma infinidade de outros formatos, inclusive o verbal, é possível apontar para uma potencialização dos processos de interação. (MELLO; TEIXEIRA, 2012, p. 1).

Essas autoras reiteram também a proximidade do texto com a tecnologia, enfatizando a necessidade de discutir esse potencial na educação. Nessa perspectiva, entende-se que a semiótica abarca diferentes semioses, ou seja, diferentes processos de significação,por meio da linguagem verbal e não-verbal,que se inter-relacionam e se mobilizam para a construção de sentido do texto. Conforme Mesquita (1997, p. 156), "A semiótica é a ciência dos signos, é a ciência de toda e qualquer linguagem; tem por objetivo analisar como se estrutura a linguagem de todo e qualquer fenômeno como fenômeno de produção de significação e de sentido". Assim, todos os elementos que compõem a produção textual integram a construção de sentido e refletimos, por meio de estudos apresentados na sequência, como isso evidencia em sala de aula.Em vista disso, Callow (2008apud Pinheiro, 2016a) apresenta categorias para a análise textual de modo a despertar o leitor para a leitura críticadetextos multimodais. Oautor sugere quea leitura seja feita nas dimensões afetiva, composicional e crítica e atenta para a intencionalidade com a qual os elementos são empregados no texto.Tendo em vista que discorrer sobre essas dimensões implicaria em ultrapassar os limites do presente artigo, não concentraremos a atenção em tais aspectos. Entretanto, poderemos refletir sobre como ocorrem as práticas pedagógicas permeadas por um olhar nessa direção ao trazer para integrar este estudoo trabalho de Pinheiro (2016a),pois focalizao letramento multimodal crítico a partir de atividades de compreensão leitora em língua espanhola, em uma escola pública cearense. Tomando como base Pinheiro (2016a), considera-se a importância dos estudospermeadospela semiótica, uma vez queesta se faz presente nas mais diversas esferas sociais nas quais os estudantes circulam. Acreditamos na relevância de despertá-los para os eventos de letramento ${ }^{4}$ dos quais fazem parte nas ações cotidianas, tais como ler um cardápio para realizar um pedido, guiar-se por meio das placas de trânsito, interagir nas redes sociais, dentre outros. Assim, cabe à escola preparar os sujeitos para essas práticas interacionais e para a compreensão dessa relação semiótica de modo a serem capazes de fazer uma leitura crítica do meio em que vivem.

A partir da presente discussão preliminar, destaca-se que, além dos documentos referenciados, discorreremos sobre o letramento crítico à luz de autores que versam a respeito

\footnotetext{
${ }^{4}$ A partir do que Soares (2014) expõe a respeito das transformações semânticas da palavra letramento ao longo das últimas décadas, é perceptível que a mudança implica no distanciamento de uma visão estruturalista para aproximar-se da visão funcional da língua. Passou-se da inferência de letrado atribuída àquele que realiza codificações, para a verificação da capacidade de uso da leitura e a escrita do sujeito para uma prática social, tal como escrever um bilhete - quer dizer, da rotulação tradicionalista para a investigação funcional. A partir de então, compreende-se que letramento "não é pura e simplesmente um conjunto de habilidades individuais; é o conjunto de práticas sociais ligadas à leitura e à escrita em que os indivíduos se envolvem em seu contexto social". (Soares, 2014, p. 72).

Em vista da compreensão apresentada acerca do letramento como prática social, destacam-se os "eventos de letramento", entendidos como situações em que o sujeito reconhece o uso do texto para uma ação social (KLEIMAN, 2005).Entende-se, portanto, que, a partir das práticas de letramento realizadas em sala de aula, o aluno terá maiores condições para agir criticamente em quaisquer eventos de letramento, dentro ou fora da escola, uma vez que essas práticas incentivam a leitura reflexiva de textos, desde os mais simples, como folders, flyer publicitários, aos mais complexos, como um artigo de opinião de revista científica, por exemplo.

${ }^{5} \mathrm{O}$ letramento críticovisto dentro desse mesmo panorama, por sua vez, pressupõe uma postura crítica diante de um texto com o intuito de compreender os privilégios e os apagamentos nas práticas sociais. (PINHEIRO, 2015).Deste modo, o aluno pode ganhar mais visibilidade, pode engajar-se mais em um posicionamento ético e político,além de empoderar-se socialmente em práticas e eventos de letramento, conforme detalhado nas práticas descritas na seção 4 do presente texto.
} 
dessa prática nas salas de aula de língua estrangeira, focalizando a complexa inter-relação entre sistema semiótico e prática social (PINHEIRO, 2016a, 2016b, 2019), associada aos estilos de aprendizagem (FILHO, 2013) e à perspectiva de ensino sociocultural (ABRAHÃO, 2012). Vale salientar que, dentre outros, a escolha desse entrelaçamento teórico foi motivada pelo fato de a BNCC, que atualmente rege quais são as aprendizagens essenciais a serem trabalhadas nas escolas públicas e particulares, abarcar tais aspectos implícita e explicitamente.

Apresentaremos primeiramente o que autores dizem sobre o uso da abordagem comunicativa de ensino voltado às necessidades dos alunos. Após, discorreremos sobre o que diz a Base Nacional Comum Curricular acerca do ensino de língua estrangeira. Para pensarmos sobre como se dá o ensino de língua estrangeira sob esta perspectiva, a seção seguinte apresenta reflexões sobre experiências de letramento crítico nas aulas de Língua Espanhola e nas aulas de Língua Inglesa, em dois contextos distintos:a escola básica regular e escola de surdos, respectivamente. E, por fim, indicaremos considerações finais acerca do presente trabalho as quais refletem a importância do ensino e aprendizagem por meio do letramento crítico para a formação cidadã.

Entendemos que o trabalho assim organizado contribui para a reflexão sobre o tema, dialogando com interessados e estudiosos da área de letramento e letramento crítico, especialmente no que se refere à língua estrangeira.

\section{Letramento e letramento crítico no ensino de línguas: ponderações iniciais}

Subjacentes à perspectiva de ensino permeada pelo conhecimento socialmente construído estão as relações do sujeito com outras pessoas e com o mundo. Vygotsky (1988); Mello e Teixeira (2012) explicitam o papel relevante da interação para o desenvolvimento da mente, de modo que as aprendizagens acontecem primeiramente no âmbito do social para, depois, serem assimiladas no individual: primeiro entre as pessoas e, depois, no nível interior.

Abrahão (2012), ao despertar para as transformações no ensino e na pesquisa de formação de professores, evidencia que a aprendizagem se configura, entre outros, por elementos do sociointeracionismo, afastando-se, portanto, do método mecanicista do behaviorismo - a saber, da transmissão de conhecimento. Para a linguista, essa corrente deixa de lado o elemento fundamental do aprendizado: "o sentido que os aprendizes atribuem aos seus mundos e os processos cognitivos ou mentais que trazem para a tarefa de aprender". (ABRAHÃO, 2012, p. 458).

Diante do exposto, compreende-se o aprendizado como um processo dialógico, em que o conhecimento é co-construído por intermédio do engajamento em práticas sociais, em que o professor é o mediador. Tendo como foco principal a interação, a prática de letramento torna-se importante não só para o ensino de línguas, mas para todas as áreas. Cabe salientar que, na BNCC (2017), inclusive, está prevista e recomendada essa configuração para o ensino de todas as disciplinas e em todos os níveis de ensino, nas escolas básicas. Desse modo, compreende-se que a relação entre o letramento e a prática estritamente individual não pode ser outra senão a dicotômica, visto que esse fenômeno

[...] é, sobretudo, uma prática social: letramento é o que as pessoas fazem com as habilidades de leitura e de escrita, em um contexto específico, e como essas habilidades se relacionam com as necessidades, valores e práticas sociais. Em outras palavras, letramento não é pura e simplesmente um conjunto de habilidades individuais; é o conjunto de práticas sociais ligadas à leitura e à escrita em que os indivíduos se envolvem em seu contexto social. (SOARES, 2014, p. 72).

No tocante a essa conceptualização, Kleiman (2016) apresenta reflexões acerca de evento do letramento. Para ela, o impacto social da escrita não é motivado pelo texto em si, mas pela situação comunicativa que se estabelece no ato da leitura, realizada em determinado contexto, por um leitor específico. A autora ainda frisa a importância de proporcionar aos aprendizes atividades 
que impulsionem o engajamento, nas quais podem ser articulados os mais diversos recursos (tecnológicos ou não), desde que estes conversem com essa esfera de ação.

Compreende-se, desse modo, que um mesmo texto pode assumir diferentes significados, construídos pela mobilização do conhecimento prévio do leitor, do contexto em que está inserido e pelas motivações a que é exposto. Frente à combinação de todos esses fatores, entende-se que a prática passa do evento do letramento para o letramento crítico, a partir do momento em que o leitor constrói um conhecimento novo, assumindo uma postura reflexiva e crítica frente ao texto e sua realidade, articulando aspectos culturais, sociais, discursivos e ideológicos no ato da leitura.

Pinheiro (2019) enfatiza a relevância dessa prática em sala de aula para a formação cidadã. Segundo a autora, "a criticidade, em sala de aula, serve para desenvolver nos alunos um posicionamento mais questionador e de resistência diante dos discursos dominantes e hegemônicos vigentes, em especial advindos dos meios de comunicação de massa”. (PINHEIRO, 2019, p. 3).

Considerando que este artigo não se presta ao esgotamento dos conceitos de letramento e letramento crítico, com base nas ideias iniciais, vamos discutir, a partir de agora, como essa prática está contemplada pela BNCC no ensino de língua estrangeira.

\title{
2 O ensino de Língua Estrangeira na BNCC
}

Para iniciar esse diálogo, partimos do princípio de que

\begin{abstract}
a aprendizagem de uma língua estrangeira não acontece num vazio emocional. Ao contrário, em sala de aula as emoções compõem o processo de ensino e aprendizagem. Toda comunicação em sala de aula é colorida por emoções: compreender e ser compreendido, vencer a inibição e o medo do ridículo, lidar com a frustração de não ser compreendido, sentir o próprio progresso ao dizer e escrever algo significativo em inglês, espanhol ou italiano. Todas essas experiências podem ter um aspecto positivo ou negativo dependendo da maneira como forem conduzidas. (MICCOLI, 2013, p. 28).
\end{abstract}

Antes de pensarmos o que e como vamos ensinar, enquanto professores de línguas, é de suma importância questionarmos quem são os nossos alunos e qual é o contexto em que esses alunos se encontram. Depois disso, é coerente perguntarmos o que faz sentido ensinar e que conhecimentos queremos construir nesse contexto. Assim, poderemos identificar, por exemplo, as crenças que os aprendizes trazem acerca do aprendizado da língua, sejam elas positivas ou negativas - pois, de alguma forma, elas permearão a nossa prática. Além disso, também serão levadas em conta a percepção dos estudantes acerca das práticas de leitura possibilitadas em sala de aula.Como a leitura e escrita não se caracterizam pela decodificação de letras, mas sim pela compreensão do todo, o docente possui um papel fundamental nesta construção. É o professor que permitirá que essas emoções, conforme Miccoli (2013), sejam produzidas de forma positiva em sala de aula. Segundo Pereira (2014, p. 149), "o professor deixa de ocupar o papel principal no processo de ensino-aprendizagem, de detentor do conhecimento, para assumir o papel de parceiro, ajudando cada aluno a progredir na aprendizagem". Aquele que ensina língua adicional, conforme Tagata (2017), precisa auxiliar esses alunos para que eles próprios entendam como a língua funciona e o ensino da gramática deve partir desse uso, de uma prática social.

Ser um professor sensível ao seu público é preocupar-se de fato com ele, é buscar identificar os diferentes estilos de aprendizagem que, conforme Brown (1993), que estabelecem conexões entre emoção e cognição. Para tornar mais claro, o autor faz um contraponto entre os estilos reflexivo e impulsivo, destacando que o primeiro é marcado por uma personalidade e humor críticos, enquanto o segundo geralmente surge de um estado emocional impulsivo. Nessa perspectiva, portanto, as emoções são subjacentes ao processo de aprendizagem, reiterando a importância de atividades motivacionais.

Perceber o ensino de língua estrangeira, em especial, de língua inglesa, como uma possibilidade de engajamento social pode ser uma forma de valorizar essas diferentes percepções 
evidenciadas pelos estudantes. É a partir delas, somadas ao que traremos de "novo", que a prática social será mobilizada. Dessa forma, consoante a BNCC, a aprendizagem de língua inglesa se inscreve por intermédio da educação linguística consciente e crítica, na qual as dimensõespedagógicae crítica estão intrinsicamente ligadas.

Tendo em vista que a Base prioriza o foco da função social e política do inglês, tratando a língua em seu status de língua franca e valorizando os diferentes usos realizados nos contextos locais, entendemos que ela corrobora com a perspectiva de ensino com a qual estamos alinhadas. Desse modo, essa regulamentação favorece a criticidade diante dos diferentes modos de ver e de analisar o mundo, os outros e a si mesmo.

Diante disso, colocamo-nos a interrogação acerca de como, afinal, impulsionar esse espírito crítico e desenvolver um olhar singular para cada estudante. Assim como em qualquer outra diretriz, na Base não encontraremos uma receita, mas é possível reconhecer algumas pistas sobre o caminho a seguir. À vista disso, amplia-se a visão de letramento para (multi)letramentos, na BNCC,

\begin{abstract}
concebida também nas práticas sociais do mundo digital - no qual saber a língua inglesa potencializa as possibilidades de participação e circulação - que aproximam e entrelaçam diferentes semioses e linguagens (verbal, visual, corporal, audiovisual), em um contínuo processo de significação contextualizado, dialógico e ideológico. Concebendo a língua como construção social, o sujeito "interpreta", "reinventa" os sentidos de modo situado, criando novas formas de identificar e expressar ideias, sentimentos e valores. (BNCC, BRASIL, 2017, p. 242).
\end{abstract}

Dessa forma, as abordagens de ensino de língua inglesa mostram-se, teoricamente, desvinculadas de crenças relacionadas a um "inglês melhor", de modo a valorizar as variações da língua, proporcionando a construção ou ampliação do repertório linguístico que rompa com crenças vinculadas à correção, pautadas no ensino de uma língua homogênea. e híbridos,

Compreende-se, portanto, que a prática pedagógicadeve ser permeada por gêneros verbais

\begin{abstract}
potencializados principalmente pelos meios digitais, possibilita vivenciar, de maneira significativa e situada, diferentes modos de leitura (ler para ter uma ideia geral do texto, buscar informações específicas, compreender detalhes etc.), bem como diferentes objetivos de leitura (ler para pesquisar, para revisar a própria escrita, em voz alta para expor ideias e argumentos, para agir no mundo, posicionando-se de forma crítica, entre outras). (BNCC, BRASIL, 2017, p. 244, grifos nossos).
\end{abstract}

Percebe-se, portanto, que o ensino de língua estrangeira, quando desenvolvido nessa perspectiva, por meio de práticas de letramento ${ }^{6}$ que possibilitem os diferentes modos de leitura promovidos pelos meios digitais, leva o sujeito a posicionar-se frente sua realidade de forma crítica e, sobretudo, a agir sobre ela.

\title{
3 Os dados em foco
}

Buscamos construir um diálogo com base em dois contextos distintos, com suas peculiaridades, mas considerando um ponto em comum: o ensino de língua estrangeira. A língua estrangeira, neste caso, em escolas públicas, sendo uma regular e outra específica para surdos. A escolha por esses dados se deu motivada pelo fato de se tratar de escolas públicas, com o ensino

\footnotetext{
${ }^{6}$ Nesse sentido, compreendem-se por práticas de letramento, conforme Fernandes (2006) e Kleiman (2016), as atividades desenvolvidas em sala de aula parapromover a capacidade leitora e escritora do aluno, com a exigência de que este exerça uma postura crítica frente ao texto.Este processo envolve criar hipóteses sobre o texto que oportunizam reflexão, estimulem a curiosidade e os desafios. Elaborar hipóteses significa relacionar o que se lê com conhecimentos prévios, adiantamento de informações e seleção das principais ideias contidas no texto.
} 
orientado pela BNCC. Desde já, atentamos para o fato de que, no momento em que foram gerados os dados por Pinheiro (2016), a Base ainda não estava implementada no Ensino Médio, masidentificamos que seu trabalho em sala de aula já caminhava nessa direção, segundo as recomendações previstas no documento. Por último, salientamos que ainda que a escola de surdos seja um contexto muito específico, não há recomendações especialmente voltadas a escolas com esse perfil, o que também nos motivou a compreender as iniciativas que estão sendo tomadas pelos professores para promoverem a aprendizagem segundo as normativas da Base.

Para este trabalho, foramconsiderados dados gerados a partir da pesquisa "Línguas orais e línguas de sinais: desafios e potencialidades na educação de surdos" ", cujoobjetivo é analisar as propostas de ensino adotadas em duas escolas para surdos da região metropolitana com ênfase para o ensino de Libras e língua portuguesa escrita como segunda língua.

A geração dos excertos 1 e 3 se deu por meio de entrevistas semiestruturadas realizadas comprofessoras, em 2018. Os registros integram a pesquisa de Steyer (2019), que parte do estudo mencionado no parágrafo anterior.As falasforam gravadas em áudio, transcritas e encontram-se disponíveis na base de dados da pesquisa mencionada. Os trechos em destaque para este artigo são da professora Aléxia ${ }^{8}$, que cursouMagistério eé formada em Letras/Inglês, possui curso de Tradutor e Intérprete de Libras e 4 anos de experiência com alunos surdos, ministrando a disciplina de Língua Inglesa. A escola à qual Aléxia pertence é uma entidade não-governamental e sem fins lucrativos, chamada Associação de Pais e Amigos dos Deficientes Auditivos (APADA), vinculada a uma escola particular de Ensino Infantil, Fundamental e Médio, localizada em um município da regiãometropolitana de Porto Alegre

O excerto 2 foi gerado a partir de conversas com professores, também em 2018,durante encontros que se realizaram em uma das escolas, com o objetivo de refletir sobre o ensino de língua portuguesa, indicando perspectivas e desafios na percepção dos docentes. As falas foram gravadas em áudio, transcritas e estão disponíveis na base de dados da pesquisa. O trecho em destaque é da professora Andréia.A educadora é formada em Letras/Português, possui Especialização em Educação para Surdos e Especialização em Orientação Educacional e 14 anos de experiência com alunos surdos. Andréia ministra aula de Língua Portuguesaem uma instituição pública estadual de Ensino Fundamental (EF),Ensino Médio (EM)e Ensino de Jovens e Adultos (EJA) da região metropolitana de Porto Alegre.

É preciso salientar ainda que, em uma sala de aula de Língua Inglesa para surdos brasileiros, há a presença de pelo menos três línguas, a Libras (oficialmente reconhecida como meio legal de comunicação e expressão dos surdos através da Lei n ${ }^{\circ}$ 10.436), a língua portuguesa escrita e a língua inglesa na modalidade escrita. Cada uma dessas línguas tem sua própria gramática, vocabulário e especificidades de uso. Deste modo, optamos por usar, neste trabalho, a expressão "Língua Estrangeira", tanto para nos referirmos ao idioma do ensino daLíngua Portuguesa (já que é a segunda língua para o surdo brasileiro), como para o ensino deLíngua Inglesa e deLíngua Espanhola, aos quais este artigo está voltado. Entretanto, ressaltamos estar cientes de que estudiosos da educação dos surdos, como Pereira (2014), Fernandes (2006), Oliveira (2007), valemse do termo L2 para a língua portuguesa e "L3", no caso da língua inglesa. Conforme Leffa (1988), o termo "Língua Estrangeira" é usado quando a comunidade não se utiliza da língua estudada na sala de aula, quer dizer, um idioma não falado oficialmente pela população local.

Também trazemos reflexões a partir da prática pedagógica realizada por Pinheiro (2016a; 2019), em experiência de letramento multimodal crítico nas aulas de língua espanhola, com alunos

\footnotetext{
${ }^{7}$ A pesquisa possui apoio da FAPERGS, Edital 02/2017, coordenada pela profa. Dra. Cátia de Azevedo Fronza. O projeto foi aprovado pelo comitê de ética da Universidade do Vale do Rio dos Sinos (UNISINOS) conforme CAAE: 79451817.6.0000.5344.

8 Tendo em vista os preceitos éticos atendidos pelos estudos aqui apresentados, registra-se que este é um nome fictício, para garantir o anonimato e preservar a identidade da respectiva docente. Tal observação diz respeito a demais participantes dos referidos estudos, cujas falas são alvo de análise neste texto.
} 
do terceiro ano do Ensino Médio de uma escola pública da periferia do Ceará, usando como principal ferramenta o livro didático.

Além do exposto, a seguinte discussão também se embasa nos dados da pesquisa de mestrado de Pinheiro (2016a), que teve como foco práticas permeadas pelo letramento multimodal crítico nas aulas de espanhol. O estudo teve caráter qualitativo, tratando-se, especificamente, de uma pesquisa-ação em sala de aula de terceiro ano do Ensino Médio (alunos com faixa etária entre 16 e 18 anos) de uma escola pública cearense na qual a pesquisadora era também professora de espanhol como língua estrangeira. Nestas aulas, foram realizadas atividades de compreensão leitora a partir dos textos presentes no livro didático Síntesis, de Ivan Martín. Foi realizada a gravação em áudio e vídeo e transcrição de dez aulas para compor o corpus do estudo. Esta pesquisa revelou a satisfatória compreensão leitora do texto multimodal e o posicionamento crítico dos estudantes sobre questões sociais que emergiram das leituras feitas.

Traremos três falas de professoras que integram a pesquisa Linguas orais e linguas de sinais: desafios e potencialidades na educação de surdos ${ }^{9}$ para análise conforme o referencial teórico sobre os aspectos mais relevantes em relação ao letramento crítico e ao que diz respeito à implementação da BNCC e às práticas escolares em língua inglesa. Além disso, traremos também, a título exemplo, uma experiência de letramento multimodal crítico em aulas de Língua Espanhola.

\section{Reflexões sobre práticas de letramento crítico na educação básica}

Tendo em vista os estudos discutidos no presente artigo, com reflexões sobre as transformações das práticas de letramento, antes voltadas para a finalidade instrumental do mercado de trabalho e atualmente como um meio de engajamento social, concentramo-nos na busca pela compreensão dessas novas formas de ensinar e aprender. Verificamos mudanças prevalecentes no contexto da sala de aula, de modo que o conhecimento deixa de ser transmitido para ser co-construído, conforme já destacado. Nessa perspectiva, vimos que, conforme destacam Mello e Teixeira (2012) e Vygostsky (1988), a interação passa a ser priorizada, de modo que o papel de protagonistadeixede ser focalizado somente no professor, e a aprendizagem ocorre de forma colaborativa. O professor exerce, sob esta perspectiva, predominantemente o papel de mediador do processo, proporcionando aos aprendizes os insumos de que necessitam para avançarem. Assim, o conhecimento ocorre primeiramente no âmbito do social (na turma) para depois ser internalizado pelo estudante.

Voltemo-nos, então, à fala da professora da educação básica, quando questionada sobre seus objetivos ao ensinar língua inglesa para seus alunos.

\section{Excerto 1}

Não adianta eu ensinar vocabulários aleatórios, não vão aprender mesmo porque não é de interesse. Aí comecei a trabalhar com projetos, aí eles me escolhem o assunto. Então eles tinham esse interesse, né? E aí eu comecei a focar mesmo no que eles queriam, né? Por que o inglês ia servir na vida deles, né? Não necessariamente na minha prática e daí funciona por que daí eles pesquisam fora, né? Quando eles veem alguma coisa assim eles já não se assustam mais eles tentam interpretar o que está acontecendo. Os objetivos são mais mesmo pro uso. (Professora Aléxia, fevereiro de 2018).

${ }^{9}$ Projeto de pesquisa desenvolvida na Universidade do Vale do Rio dos Sinos com o apoio da FAPERGS Edital PqG 02/2017, Processo n. 17255100009584. 
Conforme Excerto 1, Aléxia, professora de língua inglesa,diz que, através de várias tentativas, entendeu que, se ela ensinar a língua através de projetos e pensando como esses alunos irão compreender esse conteúdo no mundo, eles poderão chegar a um resultado mais satisfatório. Com essa manifestação, remetemo-nos a Tagata (2017), que enfatiza a importância de o professor adotar uma perspectiva de letramento em que o aluno possa apropriar-se dessa linguagem e saber usá-la fora dos limites da escola. Neste caso, a professora Alexia percebeu que deveria partir deles a busca pelo conteúdo, por algo que fizesse sentido no contexto desses alunos. Tagata (2017, p. 388) diz que "o letramento críticoobjetiva conscientizar o aluno no seu papel ativo na construção e reconstrução de sentidos, de modo que eles reflitam seus propósitos e perspectivas". A educadora, dessa forma, pode proporcionar aos alunos uma leitura crítica além daquilo que já é de senso comum, que já está no dia a dia deles.

Com os projetos que Aléxia diz adotar, podem ser oferecidos textos que circulam socialmente no contexto em questão e que estimulem a criticidade dos alunos, que os levem a refletir que nem tudo o que é dito é interpretado da mesma forma para todos. Além disso, pode ser verificado que uma verdade pode não ser a mesma para os outros colegas, que os conteúdospelos quais mostraram interesse podem ser reconstruídos em contextos culturais e sociais de maneiras diferentes. É imprescindível que se olhe para o contexto em que o uso da língua se dá.Assim, conforme Campani (2006), o alunopode praticar no seu cotidiano aquilo que está aprendendo em sala de aula.

Pinheiro (2019), por sua vez, enfatiza a relevância de explorar as múltiplas linguagens nos textos do livro didático para a formação cidadã. A professora sentiu-se instigada à pesquisa por constatar, em suas aulas, a necessidade de aprofundar, com seus alunos, as potencialidades da leitura em língua espanhola. Por isso, ela desenvolveu uma prática, ao longo de dez aulas, focalizando atividades permeadas pelo letramento multimodal crítico.

No que diz respeito às temáticas das leituras, os alunos foram expostos a textos que contemplavam questões sociais emergentes, tais como padrões culturais e ideológicos (PINHEIRO, 2019). Os aprendizes eram instigados à análise sobre a interação dos modos semióticos imagético e escrito e a influência desta na construção de sentido do texto multimodal, de modo a problematizarem as produções midiáticas com as quais a maioria dos alunos mostrouse familiarizada. A título de exemplo, citamos uma das atividades que recebeu maior atenção autora, a qualse desenvolveu a partir da Figura 1.

Figura 1 - Rambo (elemento imagético do texto “El cine, nuestro maestro emocionaP”) 


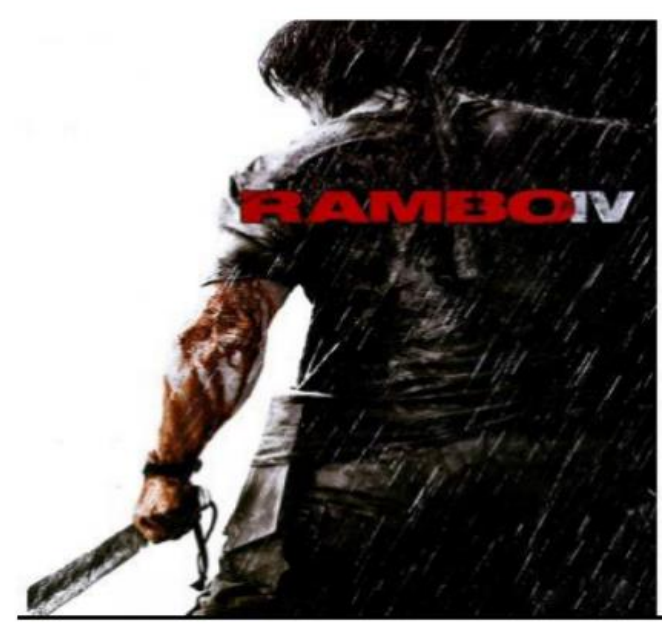

Fonte: Pinheiro, 2019, p. 466

De acordo com o que coloca Pinheiro (2019), acompreensão leitora da imagem se deu por meio da análise que, inicialmente, contemplou as impressões dos alunos, expressas oralmente, as quais se concentraram na representação do personagem de modo a qualificá-lo positivamente. No segundo momento, foram analisados os aspectos composicionais da imagem, na tentativa de construir uma interpretação. Em vista disso, alguns alunos consideraram a participação do personagem em ações de briga ou morte, devido ao sangue presente em seu corpo. A professora de espanhol e também pesquisadora relata que essas construções emergiram para além da imagem, uma vez que a maioria dos alunos evidenciou conhecer os filmes dos quais participa. Após a primeira interpretação, a docente instigou-lhes a problematizar a imagem quanto ao seu nível de abstração. Os estudantes, por sua vez, classificaram a imagem como real, por se tratar de uma pessoa, que remete a um cenário de guerra. A partir dessas identificações, foram discutidas questões relativas à desigualdade social, situações de discriminação em Fortaleza, estímulos publicitários negativos presentes na rede televisiva, entre outros.

Ao relatar tal contexto de ensino,Pinheiro (2019) destaca o percurso dos alunos, evidenciando que, ao longo das aulas, alguns estudantes passaram a manifestar seu posicionamento e fazer correlações dos textos com a realidade vivenciada. Essa prática fomentou discussões entre os alunos que, por vezes, apresentaram diferentes opiniões de forma argumentativa, as quais eram mutuamente respeitadas, ouviam as opiniões uns dos outros, independentemente de concordarem ou não. Segundo Pinheiro (2019, p. 470), este "é um dos aspectos mais valorosos da criticidade e representa um avanço no desenvolvimento do letramento multimodal crítico dos estudantes".

Ainda que haja documentos norteadores que orientem o processo de ensino-aprendizagem sob esta ótica, a concepção de ensino ancorada no letramento crítico é muito recente no sistema educacional brasileiro, de forma que veio a se tornar um quesito nos currículos escolares somente neste ano, com as exigências trazidas pela Base.

Algumas reflexões, constituídas por meio de análises partilhadas em comunicações em congressos(THEWES, STEYER E FRONZA, 2019) sobre pesquisas em andamento como de Fronza (2017) estão sendo permeadas por dados a respeito da implementação da Base que emergem de conversas com professores. Os dados refletem um quadro de incertezas por parte desses docentes que, apesar de reconhecerem a importância do documento, se sentem despreparados para reconfigurarem o currículo de modo a contemplar os aspectos previstos na BNCC, visto que não receberam capacitação ou orientações sobre como fazê-lo, como ilustra a fala deAndréia, a professora de língua portuguesa me uma das escolas de surdos. 


\section{Excerto 2:}

Esse é um documento tão, tão importante que como é que tá sendo assim, conduzido dessa forma? Isso já era pra ter há muito tempo! Nós estávamos nos encontrando, estudando juntos, trabalhando nisso, mas é uma coisa que não dá sem orientação. [...] Essa Base Nacional Comum Curricular, ela vem de cima para baixo. Então ela é um projeto de 20 anos que está se gerando então não vai ter como tirá-la. E ela veio do FNDE pra cá, agora como que o estado vai organizar, é aí a mudança. (Professora Andréia, 2018).

De acordo com o relato de Andréia, equipe diretiva e docentesreconheceram a importância e empenharam-se para a compreensão do documento, mas se sentemdesamparados e despreparados. Viam-se diante de um aparente descaso sobre forma com que estava sendo conduzido o processo de implementação da BNCC. Além disso, percebe-se a inquietude dos professores, que problematizaram o modo como a Base chegou à escola. Em outro momento, eles relataram que as considerações resultantes desses encontros para estudo, posteriormente documentadas e encaminhadas ao estado, não repercutiram no material que receberam.

Entretanto, mesmo frente a esse quadro de incertezas que os professores relataram vivenciar na escola devido à falta de orientação para a implementação das práticas prescritas pela Base,somado ao fato de se tratar de um contexto singular - o ensino de língua inglesa para alunos surdos, nota-se o empenho desses profissionais para proporcionar aosestudantes experiências significativas para o aprendizado, permeadas por práticas sociais. O professor, sabendo que o aluno tem o direito de uma aprendizagem permeada por experiências que contribuam para a ampliação dos seus conhecimentos, esforça-se para garantir que essa aprendizagem, conforme Brown (1993), se torne engajada socialmente no intuito de valorizar os diferentes olhares dos estudantes.

Tendo em vista que, na BNCC, o eixo de conhecimentos linguísticos consolida-se pelas práticas de uso, análise e reflexão sobre a língua, sempre de modo contextualizado, articulado e a serviço das práticas de oralidade, leitura e escrita, vejamos um exemplo das atividades que estão sendo guiadas por esse olhar nesta escola, a partir de outro relato da Profa. Aléxia.

\section{Excerto 3}

[...] a gente trabalha muito com vídeos, com YouTube, principalmente porque, mesmo sendo uma língua adicional de outro país, eles conseguem captar a informação, sabe? Mesmo sendo sinais um pouco diferentes assim, o contexto eles pegam... Aí muitos cartazes, cartazes, cartazes...[...] Se se encaixa na temática, no objetivo do projeto que nem eles escolheram o que eles podiam fazer dentro de algumas redes e mídias sociais, por que eles...ah mas o YouTube não é que nem o Instagram! Tem vídeo também, mas não é a mesma coisa!... Daí a gente começou a pesquisar a função de cada um...o que dá pra fazer em cada rede e mídia social, né?(Professora Aléxia, setembro de 2018).

Destaca-se que a escolha da atividade a ser realizada em sala de aula foi motivada pela percepção dos alunos sobre os diferentes veículos de comunicação. Após a comparação entre o Youtube e o Instagram, a professora optou por empreender práticas que lhes possibilitassem a reflexão por meio do reconhecimento das especificidades de cada recurso para poderem melhor explorálos e, desta forma, conforme Pereira (2014), progredir na aprendizagem.A professora, portanto, dá foco às competências de linguagem previstas na BNCC, ao utilizar-se de diversificadas linguagens 
paradefender pontos de vista e atuar criticamente diantedasquestões do mundo contemporâneo.(BRASIL, 2017).

Considera-se, portanto, a importância desse tipo de atividade em sala de aula, no mínimo, em dois aspectos: 1) a aprendizagem do surdo se dá primordialmente pelo visual; 2) as redes sociais fazem parte das vivências dos alunos, por isso é necessário incentivá-los a agir com criticidade frente às informações que circulam nessas mídias. Entendemos, assim, que essa sala de aula oportuniza aos alunos construírem o conhecimento a partir das suas vivências e pelo uso daslínguas em suas modalidades escrita e sinalizada.

Haja vista que são múltiplos os desafios para a realização de atividades que evocam a cultura digital tanto devido à falta de estrutura da escola como de formação docente, diante do exposto, destacaram-se, neste estudo, práticas pedagógicas pontuais voltadas à aprendizagem de Língua Inglesa e Língua Espanhola. Destacamos que práticas voltadas para o letramento crítico devem ser impulsionadas nestas e em outras disciplinas, dado que eventos de letramento ocorrem em todas as salas de aula e outras esferas sociais. Para isso, torna-se necessária a formação voltada para o conhecimento acerca do letramento crítico para docentes de diferentes áreas, sob perspectiva transdisciplinar de modo que ao vivenciarem os eventos de letramento assumam postura crítica frente ao discurso. Acreditamos que as práticas de letramento, como aspresentes na escola de surdos e na sala de aula de Língua Espanhola, podem integrar o cotidiano dos estudantes, dandolhes oportunidades de se posicionarem criticamente diante do contexto do qual fazem parte, direcionando-os a ações sociais efetivas e a serem autores de suas próprias históriasque passam a ser concebidas, portanto, como práticas de letramento multimodal crítico, como denominado por Pinheiro (2016a).

\section{CONSIDERAÇÕES FINAIS}

No presente trabalho, promovemos reflexões acerca do letramento crítico, ensino de língua estrangeira, considerando as orientaçõesda Base Nacional Comum Curricular. Para isso, buscamos identificar como a prática pedagógica da cultura digital contribui para a participação mais significativa e crítica nas atividades contemporâneas de linguagem na escola. Este breve recorte sobre práticas educacionaisno ensino de língua estrangeira, aponta que: i. o aprendizado só será significativo para o aluno, se conectado a seu contexto e despertá-lo para uma prática social; ii. o entrelaçamento de diferentes áreas contribui para a interação dos aprendizes com o mundo; e iii. as práticas de letramento não devem se restringir ao ensino de línguas. Percebemos, portanto, que tais reflexões sealinham às indicações trazidas pela BNCC, que visa a inserção do sujeito na sociedade por meio das suas conexões com o outro e com as esferas sociais em que se encontra.

No que se refere à indagação levantada no início deste artigo, "como a prática pedagógica da cultura digital contribui para a participação mais efetiva e crítica nas práticas contemporâneas de linguagem, em situação escolar? ", a partir das experiências com textos multimodais em sala de aula, compreendemos que as instituições, os textos e os sujeitos devem ser tratados em sua heterogeneidade,de modo que as práticas de aprendizagem impulsionem ao engajamento no contexto em que se inserem. Nesse sentido, à escola moderna e às políticas públicas cabe promover esse "letramento crítico" que dá maiores possibilidades de acesso à sociedade.

Entendemos que o professor de línguas, como um dos pilares desse processo dentro das escolas, pode estimular a conversa com outras áreas, motivado pelas práticas de letramento. Em adição a isso, é capaz de contribuir para que o letramento crítico não seja um exercício restrito nem a salas de aula de Línguas, nem à escola, mas que perpasse todas as esferas sociais.

Cabe-nos, portanto, assumir esse papel, sob três implicações dessa perspectiva de ensino: 1) reconhecer as relações entre língua, território e cultura; 2) ampliar a visão de letramento, ou letramento crítico, concebida, também, por intermédio das práticas sociais do mundo digital; e 3) desmistificar crenças de "certo" e "errado', legitimando diferentes formas de expressão da língua. 
Se o nosso agir docente for impulsionado por esses princípios, grande será a nossa contribuição para a formação de um sujeito crítico, reflexivo, capaz de identificar o lugar de si e respeitar o lugar do outro em um mundo plurilíngue e multicultural do qual fazemos parte.

\section{REFERÊNCIAS}

ABRAHÃO, Maria Helena Vieira. A Formação do Professor de Línguas de uma Perspectiva Sociocultural. SIGNUM: Estudos da Linguagem, Londrina, v. 15, n. 2, p. 457-480, dez. 2012.

BRASIL. Ministério da Educação. Base Nacional Comum Curricular: Educação é a base. Disponível em:

http://basenacionalcomum.mec.gov.br/images/BNCC_EI_EF_110518_versaofinal_site.pdf. Acesso em: 20 mai. 2019.

BRASIL. 2002. Decreto $n^{0} 5.626$, de 22 de dezembro de 2005. Regulamenta a Lei $n^{\circ} 10.436$, de 24 de abril de 2002, e o art. 18 da Lei n ${ }^{\circ} 10.098$, de 19 de dezembro de 2000. Disponível online em: http://www.planalto.gov.br/ccivil_03/_ato20042006/2005/decreto/d5626.htm. Acessoem: 02 out. 2019.

BROWN, H. Douglas. Styles and strategies. In: BROWN, H. Douglas. Principlesof Learning andTeaching. EUA: Pearson, 2006. 118-150.

CAMPANI, Daiana. Reflexões sobre ensino de línguas materna e estrangeira no Brasil: aproximações, distanciamentos e contradições. Linguagem \& Ensino, Pelotas, v.9, n.2, p. 201-221, 2006.

FERNANDES, S. F. Práticas de letramento na educação bilíngue para surdos. Curitiba: SEED, 2006.

FILHO, Augusto César Luitgards Moura. Pessoal e intransferível: a relevância dos estilos de aprendizagem nas aulas de línguas estrangeira. Revista Brasileira de Linguística Aplicada, Belo Horizonte, v. 13, n. 1, p. 313-343, 2013.

FRONZA, C. A. Linguas de Sinais e Linguas Orais: Desafios e Potencialidades na Escolarização de Surdos. Projeto de Pesquisa - Programa de Pós-Graduação em Linguística Aplicada, Universidade do Vale do Rio dos Sinos (Unisinos), São Leopoldo, 2017.

KLEIMAN, Angela B. Preciso "ensinar" o letramento? Não basta ensinar a ler e a escrever?Campinas: Cefiel - Unicamp; MEC, 2005. 60 p.

KLEIMAN, Angela B.; ASSIS, Juliana A. (Orgs.). Significados e Ressignificações do Letramento: Desdobramentos de uma Perspectiva Sociocultural sobre a Escrita. São Paulo: Mercado de Letras, 2016.

LEFFA, Vilson J. Metodologia do ensino de línguas. In: BOHN, Hilário Inácio; VANDRESEN, Paulino. Tópicos em linguística aplicada: O ensino de línguas estrangeiras. Florianópolis: Editora da UFSC, 1988. p. 211-236.

MARTINEZ, Suzana Riquelm.; PERIC, Raja Bou Assi. As Exigências Educacionais Para O Mercado De Trabalho No Século XXI. Revista Interfaces: ensino,pesquisa e extensão,Suzano, v. 1, nº 1 , p. 5-22, 2009, jul./dez.

MELLO, Elisângela de Fátima Fernandes de; TEIXEIRA, Adriano Canabarro. A interação social descrita por Vigotski e a sua possível ligação com a aprendizagem colaborativa através das 
tecnologias de rede. In: IX SEMINÁRIO DE PESQUISA EM EDUCAÇÃO DA REGIÃO SUL, 2012, Caxias do Sul. Anais. Caxias do Sul: UCS, 2012. Disponível em: http://www.ucs.br/etc/conferencias/index.php/anpedsul/9anpedsul/paper/viewFile/6/871. Acesso em: 03 nov. 2019.

MESQUITA, Rosa Maria. Comunicação não-verbal: relevância na atuação profissional. Revista Paulista de Educação Física, São Paulo, v. 11, n. 2, 155-163, 1997. Disponível em: http://www.revistas.usp.br/rpef/article/view/138567/133974. Acesso em: 03 nov. 2019.

MICCOLI, Laura. Aproximando teoria e prática para professores de línguas estrangeiras. Belo Horizonte: Fino Traço, 2013.

OLIVEIRA, D. F. A. 2007. Professor, tem alguém ficando para trás! As crenças de professores influenciando a cultura de ensino/ aprendizagem de LE de alunos surdos. Dissertação (Mestrado em Linguística Aplicada) - Programa de Pós-Graduação do Departamento de Línguas Estrangeiras, Universidade de Brasília (UNB), Brasília, 2007.

PEREIRA, Maria Cristina da Cunha. O ensino de português como segunda língua para surdos: princípios teóricos e metodológicos. Dossiê: educação bilíngue para surdos: políticas e práticas (edição especial). Educar em Revista, Curitiba, n. 2, p. 143-157, 2014. Disponível em: http:/ /www.scielo.br/scielo.php?pid=S010440602014000600011\&script=sci_abstract\&tlng=pt. Acesso em: 23 set. 2019.

PINHEIRO, Michelle Soares. O letramento multimodal crítico: o discurso discente sobre política nas aulas de espanhol. Revista Brasileira de Linguística Aplicada,Aheadof print. 2019. Disponível em: http://www.scielo.br/scielo.php?script=sci_abstract\&pid=S198463982018005004104\&lng=en\&nrm=iso\&tlng=pt. Acesso em: 11 set. 2019.

PINHEIRO, Michelle Soares. Letramento crítico: perspectivas do ensino-aprendizagem em língua espanhola para idosos. Revista Interletras, Mato Grosso do Sul, n. 20, vol. 3, 2014-2015, p. 1-13. Disponível em: http://www.interletras.com.br/ed_anteriores/n20/artigos/13.pdf. Acesso em: 11 set. 2019.

PINHEIRO, Michele Soares. Investigando o Letramento Multimodal Crítico de Alunos de Espanhol do Ensino Médio de uma Escola Pública de Fortaleza-Ce. 2016a. 317 f. Dissertação (Mestrado em Linguística Aplicada) -Programa de Pós-graduação em Linguística Aplicada, Universidade Estadual do Ceará (UECE), Ceará, 2016.

PINHEIRO, Michele Soares. Multimodalidade e Letramento Visual na sala de aula de Língua Espanhola: análise de uma atividade de produção escrita. Revista Brasileira de Linguística Aplicada, v. 16, n. 4, p. 575-593, 2016b. Disponível em: http://www.scielo.br/scielo.php?pid=S198463982016005002102\&script=sci_abstract\&tlng=pt. Acesso em: 18 mai. 2019.

SOARES, Magda. Letramento:um tema em três gêneros. 3. Ed. Belo Horizonte: Autêntica Editora, 2014.

TAGATA, W. M. Letramento crítico, ética e ensino de língua inglesa no século XXI: por um diálogo entre culturas. Revista Brasileira de Linguística Aplicada, v. 17, n. 3, p. 379-403, 2017.

THEWES, J. D.; STEYER, D.; FRONZA, C. A. A dinâmica e desafios da aprendizagem de língua portuguesa escrita para alunos surdos na perspectiva da educação bilíngue. In: VI 
ENCONTRO INTERNACIONAL DO INTERACIONISMO SOCIODISCURSIVO, 2019, São Leopoldo.Comunicação apresentada. São Leopoldo: Unisinos, 2019.

VYGOTSKY, L. S. Pensamento e linguagem. Porto Alegre: Artes Médicas, 1988.

Submetido em 19/11/2019

Aceito em 17/02/2020

Publicado em 30/04/2020 